\title{
AS HISTÓRIAS DE SALA DE AULA NA FORMAÇÃO ACADÊMICO- PROFISSIONAL DE PROFESSORES NO PIBID/FURG
}

\author{
Aline Machado Dorneles ${ }^{\mathrm{i}}$ \\ Maria do Carmo Galiazzi ii \\ Suélen Altenhofen ${ }^{\text {iii }}$
}

\begin{abstract}
Resumo: Apresenta-se a história construída na formação de professores no Programa Institucional de Bolsa de Iniciação à Docência (PIBID), desenvolvido na Universidade Federal do Rio Grande (FURG) desde o ano de 2009. O presente texto centra-se no processo de escrita de histórias de sala de aula nas Rodas de Formação acadêmico-profissional de professores e licenciandos (DINIZ-PEREIRA, 2011, SOUZA, 2011), sendo uma das atividades propostas no âmbito do PIBID/Institucional da FURG. Abordam-se os pressupostos teóricos e metodológicos no processo de escrita de histórias de sala de aula, centrado na escrita narrativa, como modo de se constituir professor em Rodas de Formação (CLANDININ; CONNELLY, 2011, SOUZA, 2011). Os resultados de uma avaliação on-line proposta no âmbito do PIBID/Institucional na FURG no ano de 2012 são discutidos como modo de perceber a contribuição do PIBID e a importância das histórias de sala de aula para licenciandos e professores participantes do processo de formação. Argumenta-se a importância de continuidade e reconhecimento do PIBID como política de formação de professores, a partir da potência das Rodas de Formação, das histórias de sala de aula vividas na sala de aula, das aprendizagens e do trabalho colaborativo na formação docente.
\end{abstract}

Palavras chave: Formação de Professores; Escrita Narrativa; Roda de Formação.

\section{LAS HISTORIAS DE CLASE EN LA FORMACIÓN ACADÉMICA-PROFESONAL EN EL PIBID / FURG}

Resumen: Presenta la historia construida en la formación docente en el Programa Institucional de Iniciación de subvención para la enseñanza (PIBID) desarrollado en la Universidad Federal de Rio Grande (FURG) desde 2009. Este documento se centra en las historias del proceso de escritura aula en las rondas de formación académicas y profesionales profesores y estudiantes universitarios (DINIZ-PEREIRA, 2011 SOUZA, 2011), una de las actividades propuestas en el marco del PIBID/Institucional FURG. Se ocupa de los supuestos teóricos y metodológicos en el proceso de escribir historias centradas en el aula de escritura narrativa como una forma de proporcionar la formación del profesorado en las rondas (Clandini; Connelly 2011, SOUZA, 2011). Los resultados de una propuesta de evaluación en línea dentro del PIBID/Institucional en FURG en 2012 se analizan como una manera de darse cuenta de la contribución de PIBID y la importancia de las historias en el aula a estudiantes y profesores que participan en el proceso de formación. Se argumenta la importancia de la continuidad y el reconocimiento de PIBID como política de formación docente, a partir de la potencia de las rondas de formación, las historias de aula vivían en el aula, el aprendizaje y el trabajo colaborativo en la formación docente.

Palabras Clave: Formación de Profesores, Narrativa Escrita, Rondas de Formación. 


\section{Introdução}

O presente artigo apresenta a história construída na formação de professores no Programa Institucional de Bolsa de Iniciação à Docência (PIBID) desenvolvida na Universidade Federal do Rio Grande (FURG), desde o ano de 2009. Neste, aborda-se o processo de escrita de histórias de sala de aula em Rodas de Formação (SOUZA, 2011), sendo uma das atividades proposta no âmbito do PIBID/Institucional da FURG. Assume-se o argumento de que a escrita narrativa nas Rodas de Formação do PIBID/FURG contribui para a formação acadêmico-profissional de licenciandos e professores da educação básica e da universidade.

Propõem-se nas Rodas de Formação do PIBID da FURG o termo formação acadêmicoprofissional no lugar de formação inicial e continuada conforme sugerido por Diniz-Pereira (2011). Pois, conforme o autor, “[...] é importante compreender a prática profissional como um lugar de formação e produção de saberes e estabelecer ligação entre as instituições universitárias de formação e as escolas da educação básica". (Diniz-Pereira, 2011, p. 213). O PIBID/FURG busca promover Rodas de Formação acadêmico-profissional por meio da escrita, leitura e conversa com as histórias de sala de aula narradas em ambiente virtual de aprendizagem, a Plataforma Moodle, espaço destinado para registro das atividades do projeto. As histórias tornam-se dispositivos da formação, promovendo a partilha de experiências da formação profissional do professor experiente da escola, com a formação acadêmica do licenciando na universidade.

O presente texto está organizado em três momentos. Primeiramente, com uma narrativa da história do PIBID na FURG, com a primeira edição do projeto em 2009, do qual teve início no primeiro edital proposto no ano de 2007 pela CAPES, com as quatro licenciaturas prioritárias naquele momento: Química, Física, Biologia e Matemática. Com a participação nos demais editais, o PIBID/FURG teve a possibilidade de ampliar o número de bolsas, contemplando as demais áreas e cursos de licenciatura da instituição. O programa vem, nos últimos anos, construindo história na formação de professores, com a aposta nas Rodas de Formação, como modo de aprender a ser professor (SOUZA, 2011).

Num segundo momento, apresentam-se os aportes teóricos e metodológicos no processo de escrita de histórias de sala de aula, centrado na pesquisa narrativa como modo de se constituir professor em Rodas de Formação (CLANDININ; CONNELLY, 2011, SOUZA, 2011). A experiência de desenvolver a escrita de histórias de sala de aula em roda é narrada por uma 
professora universitária, coordenadora do subprojeto do PIBID/Química, a partir das histórias construídas e vividas nas Rodas de Formação, nos encontros semanais de formação, bem como nas histórias de sala de aula de cada participante do projeto.

Finaliza-se com a apresentação dos resultados de uma avaliação on-line proposta no âmbito do PIBID/Institucional na FURG no ano de 2013. Apresenta-se a avaliação das razões que motivaram a participação no programa e qual a importância do processo de escrita das histórias de sala de aula na formação do bolsista licenciando e professor supervisor participante do PIBID.

\section{A história do PIBID na FURG}

A história de formação de professores na FURG começa a ser outra com o desenvolvimento do Programa Institucional de Bolsa de Iniciação à Docência (PIBID), desde 2009. Inicialmente, contava com a participação de quatro cursos de licenciatura, os quais compuseram os subprojetos da Química, Física, Biologia e Matemática, que era o foco do edital, dada a falta de professores para atuar nessas disciplinas e o elevado índice de desistência de graduandos nas quatro áreas de ensino em questão (BRASIL, 2007). O projeto pretendeu intensificar e qualificar um conjunto de ações na formação de professores, em que o incentivo à docência é inextricavelmente ligado à formação do professor em exercício.

No ano de 2010, o projeto ampliou-se potencialmente na FURG, com envolvimento de dez cursos de licenciatura, com aumento no número de bolsistas para 80 licenciandos, 14 professores supervisores. Com isso, mais de 2000 alunos das escolas de educação básica foram beneficiados com o projeto. Nesse sentido, destaca-se sua relevância no incentivo à docência, na parceria da universidade com o ensino básico (escolas públicas), na oportunidade de formação continuada para professores em exercício e na melhoria do ensino e da aprendizagem dos alunos.

Logo no ano de 2012, o PIBID/FURG totaliza a participação de 15 subprojetos: 13 disciplinares e 02 projetos interdisciplinares (Gestão Escolar e Educação Ambiental); com a participação de mais de 300 licenciandos bolsistas, 44 professores supervisores, 15 coordenadores de área, 2 coordenadores da área de gestão educacional e 2 coordenadores institucionais, abrangendo vinte e duas escolas da rede pública de Educação Básica no município de Rio Grande / RS. 
Neste mesmo ano, foi elaborado e aprovado o curso de especialização Narrativas na Docência para os professores supervisores do PIBID/FURG. Não foi um processo simples de desenvolver pelos entraves administrativos e burocráticos advindos de sua originalidade, embora a ideia seja encantadora e desafiadora. $\mathrm{O}$ curso contou com 31 professores aprovados e, destes, alguns trabalhos de conclusão de curso foram disponibilizados e selecionados para publicação em livro do projetoiv.

No ano de 2014, a história do PIBID/FURG continua com um número de bolsas próximo ao edital anterior, com a participação dos cursos de Licenciatura em Ciências e Licenciatura em Letras Espanhol na modalidade a distância, com a realização de encontros semanais de formação via videoconferência e produção de webfólios no ambiente virtual.

Devido à complexidade da profissão, a organização das atividades do PIBID/FURG está pautada na articulação entre a teoria e a prática em ações que envolvem a Universidade e a Escola de modo conjunto. O que isso significa? Que o planejamento das ações educativas foi feito a partir da sala de aula da rede de educação básica com o intuito de produzir compreensão a questionamentos dela advindos. Isso exige aprofundamento teórico que gera maior compreensão dessa sala de aula. Não só dela, mas a partir dela também compreender melhor a sala de aula da formação inicial. Além disso, amplia-se a compreensão da complexidade da profissão e as exigências que se apresentam na formação de professores em um contexto mais amplo que é a educação.

A participação no projeto se dá como forma de incentivo à carreira docente, em que o processo de formação está relacionado com a formação do professor da escola, com a partilha de experiências e desenvolvimento de atividades que viabilizam a contextualização na sala de aula da educação básica. Dessa forma, a escola permite uma aproximação dos licenciandos nas salas de aula e uma relação integrada com a universidade, em que o professor, além de contribuir com a formação dos licenciandos, se encontra em formação continuada.

\section{As rodas de formação acadêmico-profissional de professores}

A formação inicial de um professor, quando compreendida em Rodas de Formação acadêmico-profissional, torna-se importante e fundamental para que o futuro profissional vivencie as situações reais da sala de aula e também compreenda a importância das relações de 
partilha dentro da própria escola que está atuando. A partilha entre o professor experiente e o licenciando é essencial para o crescimento de ambos, sendo compreendido por professor experiente aquele que desenvolveu com o tempo certas estratégias que ajudam a resolver problemas típicos do contexto escolar.

Não se trata de um acompanhamento do licenciando apenas por especialistas em educação, mas do acompanhamento feito pelo professor da escola, do olhar do mais experiente, do auxílio na integração com a coordenação, direção e demais professores da instituição de ensino. Diniz-Pereira (2011) discute a influência positiva da participação em experiências educacionais na escola e afirma que:

A maior parte dos licenciandos apontou a participação em tais experiências como decisiva em sua opção pela profissão de professor, em função de uma maior respeitabilidade que passam a conferir ao trabalho docente ao vivenciar a complexidade dos desafios do fazer pedagógico e da descoberta do prazer proporcionado pelas relações pessoais que a dinâmica de sala de aula oportuniza (p. 48).

Entende-se que o licenciando poderá aprender a profissão docente no decorrer do seu trabalho na escola, se estiver atento às características e à realidade em que está presente. A escola é um espaço de formação do professor, pois nela as experiências coletivas poderão se transformar em conhecimento profissional por meio da escrita narrativa dessas experiências e na conversa em Roda como modo de construir decisões coletivas tomadas a partir desses diálogos.

O processo formativo em Rodas possibilita que os professores, ao narrarem suas histórias de sala de aula, encontrem espaço para dialogar e refletir a respeito de suas práticas pedagógicas (WARSCHAUER, 2001; SOUZA, 2011). As Rodas de Formação no PIBID/FURG são constituídas por professores experientes do ensino básico, licenciandos e professores da universidade. Na busca por compreender o sentido e o significado das Rodas, dialoga-se inicialmente com Warschauer (2001, p. 300), que assim as define:

Quando falo em Rodas, entretanto, não me refiro à estrutura apenas, mas à qualidade da interação, às partilhas que elas facilitam. Haver espaços e tempos definidos para o encontro das pessoas em círculo não é suficiente, mas é a qualidade das trocas estabelecidas no processo de partilha que propicia o desenvolvimento criativo individual e grupal. 
Também se atribui o sentido das Rodas, baseado nas contribuições de Souza (2011, p.152), segundo as quais, “o professor, ao narrar sua experiência na Roda, partilhando-a, a ressignifica para si. Ao mesmo tempo, o outro se torna um interlocutor potencialmente aprendente nesse processo; o próprio significado de partilha implica esse pressuposto". Nas Rodas de Formação, os professores contam suas histórias e, ao contarem de si, também contam a respeito dos outros que os constituem e, ao contarem desses outros, contam de si (SOUZA, 2011).

As Rodas de Formação, que constituem em histórias de sala de aula, envolvem outras Rodas em cada história que se narra. Acredita-se que o sentido e o significado da escrita em Rodas seja esse mesmo: o de envolver-se na história do outro, de criar Rodas de Formação em diferentes espaços da escola e de narrar às experiências vivenciadas nas diferentes Rodas (DORNELES, 2013). O ato de narrar histórias em Rodas de Formação favorece a partilha de experiências, proporcionando ao outro que lê, pensar e refletir sobre sua formação (WARSCHAUER, 2001). O diálogo com o outro e consigo mesmo intensifica o processo de formação do professor, pois, nessa partilha de saberes e escritas, encontra-se o sentido de exercer a profissão de educador.

Nos espaços de formação acadêmico-profissional de professores é importante que se desenvolva a escrita narrativa da prática docente, uma escrita que expresse a autoria e a sala de aula do professor. Quando desenvolvida nas Rodas de Formação, pode proporcioná-lo explicitar, em cada história, cenas mais detalhadas da sua sala de aula, expressando sua inventividade e criatividade. Ao narrar cada fato, pode também dialogar e partilhar suas experiências. Nas Rodas, as histórias também são lidas por outros professores, permitindo que outras histórias possam ser criadas e narradas. Nesse sentido, o professor pode "apropriar-se das experiências vividas através da escrita, transmitindo-as a outros, evocando argumentações e emoções, favorecendo, portanto, a construção da autoria, isto é, da autoridade de si” (WARSCHAUER, 2001, p. 190).

Os docentes, quando narram suas histórias de sala de aula nas Rodas de Formação, refletem, aprendem e conversam a respeito de suas teorias, vivências da sala de aula e práticas pedagógicas. Sendo assim, assume-se as Rodas de formação acadêmico-profissional como argumento central no PIBID/FURG como a escrita de histórias de sala de aula dos professores do ensino básico, licenciandos e professores da universidade, configurando-se, de tal modo, 
uma Roda que proporciona a constituição de outras em que são narradas a sala de aula, o laboratório, a biblioteca e outros espaços da escola.

\section{As histórias de sala de aula no pibid/furg}

O PIBID/FURG propõe como aportes teóricos e metodológicos a formação acadêmicoprofissional em Rodas de Formação e a escrita narrativa como modo de pensar a sala de aula e de fazer pesquisa na formação de professores (CLANDININ; CONNELLY, 2011, DINIZPEREIRA, 2011, SOUZA, 2011, DORNELES, 2013).

A escrita narrativa torna-se um dispositivo de formação acadêmico-profissional, em que os licenciandos percebem-se professores e pesquisadores das suas próprias experiências na sala de aula. Por meio do registro narrativo, os sujeitos podem ser capazes de darem-se conta das suas limitações, sendo, assim, impulsionados a buscarem argumentos, a divulgá-los a outros sujeitos e a modificar sua ação.

Na primeira edição do projeto, no ano de 2009, a proposição das histórias de sala de aula, foco de discussão do presente texto, era de narrar uma história por mês no Ambiente Virtual de Aprendizagem (AVA), Plataforma Moodle. As histórias eram lidas e dialogadas no ambiente, num exercício de escrever o que a história do outro me faz pensar. Desse processo foi publicado o primeiro álbum do PIBID/FURG, em que as histórias foram ilustradas representando os detalhes da narrativa. $\mathrm{O}$ álbum apresenta uma diversidade de temas relativos a educação e a formação de professores, fortalecendo a aposta da escrita de histórias de sala de aula (GALIAZZI; PAULITSCH, 2011).

O ambiente virtual facilita a visualização das histórias escritas, porém o número elevado de participantes fazia com que nem todas as histórias fossem lidas por todos. Por isso, a partir do ano 2011 a escrita das histórias de sala de aula passou a ser escrita e dialogada semestralmente no AVA de cada subprojeto. As histórias começaram a ser lidas e discutidas nas Rodas de Formação e, assim, oportunizou-se um maior comprometimento com a escrita e ampliou-se a possibilidade de diálogo sobre o tema narrado pelo autor. As contribuições, advindas do olhar crítico do outro, possibilitam a quem escreve repensar, refletir e reescrever seu relato. "É um momento em que se "fixa" textualmente a experiência, e ela começa a alcançar seu grau de objetividade, até chegar o momento de ser publicizada" (SUÁREZ, 2008, p.118). 
A escrita das histórias de sala de aula oportuniza aos professores e licenciandos sentirem-se autores de suas práticas educativas. Nesse sentido, o PIBID/FURG aposta na publicação dos álbuns de histórias de sala de aula, que está, atualmente, na sua quarta edição (GALIAZZI; PAULITSCH, COLARES, 2012; 2013; 2014). Entende-se que é importante que essas histórias sejam publicizadas, reescritas, recontadas não só para o professor que narra, mas também para o professor que a lê. Assim, a escrita de histórias torna-se um dispositivo de formação, que permite ao professor narrar seus sentimentos, frustrações e avanços, e potencializar o trabalho coletivo, a partilha de experiências nas Rodas de Formação.

Portanto, por meio da escrita de histórias de sala de aula e na conversa a respeito do narrado em Roda, os licenciandos e professores partilham de suas experiências e expectativas com outros interlocutores. Ao narrar, eles partilham e conversam com outros colegas numa linguagem prática, com suas próprias palavras, pois, por meio da escrita e da leitura de histórias, os professores podem discutir problemas, dúvidas e aflições comuns (SUÁREZ, 2008).

As histórias de sala de aula nas Rodas do PIBID tornam-se espaços privilegiados de questionamento e investigação da prática profissional. Nas Rodas, o licenciando pode partilhar as experiências, seus medos e suas angústias em estar na sala de aula por meio das suas histórias, além de construir materiais para as aulas e aprofundar estudos teóricos. São oportunidades de diálogo, construção de conhecimento e valorização da formação do professor.

Desse modo, o PIBID é um importante espaço de aprendizagem e investigação, permeado sempre pela linguagem escrita como modo de documentar as experiências construídas no processo de formação. Porém, o escrever não é tarefa fácil. Nesse sentido, a narrativa a seguir apresenta a experiência de uma professora coordenadora do subprojeto do PIBID/Química ao vivenciar e experienciar o processo de escrita narrativa na Roda:

Contar as experiências de um trabalho coletivo não é tarefa fácil, pois afinal quando somos coletivos? E quando somos um grupo? Penso que o trabalho em grupo pode vir a ser um coletivo, quando os sujeitos colocam-se como aprendentes com o outro.

A reflexão acima encaminha minha narrativa reflexiva das experiências de um grupo que vem se constituindo num coletivo. O olhar de cada um para as experiências que constroem no coletivo é diferente, por isso, narro minhas experiências construídas e reconstruídas com os outros. No dia 07 de abril de 2014, iniciamos nossas atividades e, daquele dia em diante, nossas tardes de segundas-feiras não foram mais as mesmas, pois decidimos por um trabalho em grupo. Alguns que ali chegavam já se sentiam num coletivo, afinal, tinham alguns anos de trabalho e 
amizade construídos em outros grupos, porém agora era diferente! Havia outras pessoas, outro espaço de encontro, outra proposta de formação.

Inicialmente, nos conhecemos por meio das nossas histórias de vida e formação, foi muito bacana! Aproximamo-nos já como coletivo nessa atividade. As histórias se entrelaçavam por meio das escolas o qual estudamos na infância, nos desenhos animados da época, os jogos de videogame, dentre outras lembranças.

Os meses de trabalho foram se passando, a cada segunda-feira muitas aprendizagens, conversas e belíssimos cafés. Os licenciandos foram estabelecendo a parceria com o professor supervisor e nas conversas sobre a experimentação fomos tomando decisões de propostas de planejamento para o semestre. A ideia foi vivenciar com mais calma e intensidade cada momento de formação, então desenvolvemos uma atividade experimental em cada escola. A experimentação para alguns professores não se tornava tão presente na sala de aula. Mas isso não foi problema, pois agora decidimos ser coletivo, e quando se trabalha na parceria é possível realizar a experimentação e fazer dela um acontecimento na sala de aula e na nossa formação.

Fazer da experimentação um acontecimento é possibilitar que algo nos aconteça, que algo nos desacomode, que algo nos desconstrua no coletivo. O sentido da experiência para Larrosa é esse, que possa ser aquilo que nos acontece, que possa ser conversado e escrito nas histórias de sala de aula de cada professor supervisor e licenciandos. A escrita da experiência de cada um é um momento único, afinal é o que "eu decido contar" e partilho com o coletivo.

O envolvimento com a escrita precisa ser intenso, é preciso escrever para pensar, conforme nos diz Mário Osório Marques no seu livro "Escrever é preciso". Por isso, penso que precisamos nos envolver mais com o processo da escrita, isso não quer dizer que não estamos escrevendo, estamos sim! Mas é torná-la mais envolvente para quem escreve e para quem lê e, para isso, o olhar do outro é importante, pois me faz pensar, repensar e reescrever. Relemos as histórias que escrevemos? Será que o outro lê o que escrevo? Como dialoga com que escrevo?

Fica o convite para os leitores que chegaram até o final dessa narrativa reflexiva, que expresse seus sentimentos e ideias de como podemos intensificar nosso processo de escrita das histórias de sala de aula (Coordenadora PIBID/Química - história de sala de aula, 2014) ${ }^{\mathrm{v}}$.

A aposta é na escrita narrativa sobre sua sala de aula e o ser professor. O exercício da escrita permite a avaliação da sua prática, um espaço de repensar e intervir de forma crítica tanto na própria ação quanto no seu potencial de conhecimento, já que exige, além de tempo, dedicação. Nesse sentido, Dorneles e Galiazzi (2012, p.566) acreditam que: 
Exercitar a escrita narrativa na formação permanente do professor é uma forma de pensar, repensar e refletir a respeito da sala de aula, das práticas pedagógicas e da vida profissional. Nesse sentido, o projeto PIBID/FURG aposta na escrita de histórias da sala de aula como modo de o professor compreender-se em formação, buscando perceber melhor as teorias que suportam sua prática pedagógica.

A aposta na escrita narrativa no projeto possibilitou a publicação das histórias de sala de aula. Até o momento, foram publicados quatro álbuns, com histórias dos licenciandos e professores supervisores dos subprojetos. A intenção é oportunizar o sentimento de autoria de sua prática educativa, como também fazer circular essas histórias em outras Rodas de Formação, outras instituições de ensino e cursos de licenciatura.

Assim, entende-se que o PIBID vem construindo histórias na formação de professores, com alcance dos objetivos e metas, do licenciando aprimorar e aprender a cada situação, ao vivenciar as diferentes realidades da escola e da docência. Com o PIBID, é possível o trabalho coletivo, discussão de ideias, desenvolvimento da escrita, a exposição e defesa de ideais, além da aproximação da escola, da sala de aula e dos alunos da educação básica, ou seja, da realidade escolar. Nesse contexto, licenciandos, professores e alunos das escolas aprendem juntos, em Rodas de Formação na escola e na universidade, em um processo de formação acadêmicoprofissional.

\section{O que dizem os pibidianos sobre o processo de formação?}

Com o intuito de investigar a importância e as contribuições do processo de formação acadêmico-profissional proporcionado no PIBID/FURG, planejou-se um questionário de avaliação on-line, desenvolvido no segundo semestre de 2013. Nesse período, o projeto realizava suas últimas atividades, com os editais em vigor do ano de 2011 a 2012 e contava com a participação de cerca de 290 participantes, entre eles, licenciandos, professores supervisores e coordenadores dos subprojetos.

O questionário foi respondido por coordenadores, professores e bolsistas do PIBID/FURG, com o objetivo de conhecer um pouco mais dos sujeitos que participavam do projeto e analisar a visão com que o discente se percebe naquele espaço. No período de realização da pesquisa, 226 (licenciandos e professores supervisores das Escolas) responderam o questionário. 
Os bolsistas do PIBID responderam algumas indagações referentes à participação no projeto. Entre dados pessoais e imersão no projeto, algumas questões eram relacionadas à participação no projeto, contando com cinco questões descritivas, que visavam procurar as influências do PIBID na vida acadêmica e na constituição da sua identidade profissional.

A investigação a respeito da avaliação dos participantes sobre o projeto é importante, já que os sujeitos estão imersos nas escolas e salas de aula, vivenciando experiências de iniciação à docência e, por esse motivo, suas histórias devem ser compartilhadas e discutidas. Além das reuniões dos subprojetos e das escritas registradas e reflexivas sobre a participação, a compreensão do projeto no âmbito institucional ajuda a compor o contexto e a formação de cada licenciando, bem como analisar de que forma o programa intervém no processo discente.

O questionário foi composto por questões de cunho pessoal e qualitativo a respeito do projeto. As questões de cunho qualitativo foram: Qual a principal razão que motivou sua participação no PIBID? Quais as atividades realizadas no PIBID motivaram sua compreensão pela docência? Qual a importância das histórias de sala de aula na sua formação docente? Qual a importância da escrita coletiva no portfólio?

A seguir, apresentam-se as razões que motivaram a participação no PIBID/FURG, como também, a importância das histórias de sala de aula na formação do bolsista licenciando e professor supervisor participante desse programa. Para isso, realizou-se um processo de análise qualitativa, utilizando-se a metodologia da Análise Textual Discursiva que consiste na unitarização das informações, a categorização e a escrita das emergências e compreensões do processo de formação (MORAES, GALIAZZI, 2011).

\section{O PIBID como espaço de partilha das experiências da docência}

A imersão na realidade escolar é um dos aspectos que o licenciando procura vivenciar durante o curso de licenciatura e, quando participa do PIBID, essa experiência é possível com a aproximação da sala de aula e do ambiente escolar, muitas vezes, antes da experiência de estágio supervisionado. O interesse na sala de aula e no dia a dia da escola é percebido e narrado pelos bolsistas licenciandos do PIBID/FURG, de modo que expressam a motivação pelo exercício da docência e destacam a escrita como forma de registro dessas experiências. Destaca-se a resposta do licenciando quando afirma que: 
É muito importante a escrita das histórias, pois, elas são experiências que vivemos na escola, essas histórias são detalhes que percebemos em sala de aula, e são acontecimentos que iremos presenciar durante toda nossa história dentro de uma escola (Bolsista licenciando - PIBID/Interdisciplinar - Gestão Escolar, 2013).

É na vivência da escola, na aproximação dos alunos, nas ações e iniciativas que podem ser tomadas a fim de promover a aprendizagem, que os licenciandos buscam fazer do PIBID, entre outros fins, um meio para melhorar para a educação básica. As experiências de sala de aula mostram a realidade que o aluno vive na escola e, portanto, a realidade que o professor encontra quando em exercício da docência. A licencianda do PIBID/Química diz que: "Conhecer melhor o trabalho de um professor, poder ter contato desde o início de minha formação com a escola, possibilita perder certos medos e receios” (2013).

Reforça-se o argumento de uma formação que promova a aproximação entre escola e universidade, e a parceria entre elas, para que o licenciando perceba a importância de ambas na sua formação. O PIBID fortalece o processo de constituição docente, na medida em que há um vínculo com a escola, com os alunos e com os professores, sendo as experiências vivenciadas na sala de aula reflexões a respeito do exercício de professor.

Cursar licenciatura e futuramente ser um professor é uma tarefa árdua e por isso devemos sempre estar o mais preparado possível. Como os estágios no curso de Química acontecem no meio do curso, sinto que precisava estar preparada para enfrentar essa profissão docente o quanto antes. Frente a isso, surgiu à possibilidade de ingressar no PIBID e ter contato mais direto com a sala de aula e o espaço escolar, sendo assim achei uma ótima oportunidade para meu aprendizado individual e até mesmo coletivo (Bolsista licenciando-PIBID/Química, 2013).

Desta forma, a escola e a universidade são compreendidas como lugares da formação e possibilitam vivências de experiências de sala de aula, o planejamento e o desenvolvimento de atividades no coletivo. Assim, o professor experiente sente-se incentivado e responsável pela formação do licenciando, sendo este um trabalho de parceria e de coformação docente. Como sugere Diniz (2008), uma formação acadêmico-profissional deve permitir a relação e a parceria entre a universidade e escola de modo que ambos possuam responsabilidade no processo de formação.

As histórias de sala de aula, quando partilhadas e conversadas em Rodas de Formação, proporcionam pensar na formação levando em consideração as experiências vividas na escola. 
Escrever histórias nos faz refletir e analisar nossos momentos vividos. Sempre trazendo inquietações a nossa prática e ser professor é ser questionador, aperfeiçoável, transformador, inquieto e reflexivo. Assim então, a escrita nos trás não somente o registro das aulas, mas também uma oportunidade de poder repensar o que temos feito como educadores, sendo de suma importância para o crescimento pessoal e coletivo (Bolsista licenciando - PIBID/Química, 2013).

Dessa forma, as Rodas de Formação no PIBID possibilitam ao licenciando um convívio maior com o professor da educação básica e com o ambiente escolar, fazendo a articulação da escola com a universidade ser intensificada e possibilitando que os professores da educação básica, os licenciandos e os professores da universidade estejam juntos, em Rodas. Estes problematizam suas teorias da sala de aula e tramam suas histórias por meio das partilhas. Cada um, com sua história individual, suas características e talentos singulares, contribui na construção partilhada (WARSCHAUER, 2001).

Além disso, a imersão no ambiente escolar é uma das principais razões para que o bolsista reflita sobre a escolha da licenciatura. Muitos licenciandos acreditam que é no exercício da docência, na prática da sala de aula que a decisão pela formação docente se dá como sucesso ou insucesso. "A principal razão foi que eu tinha dúvidas sobre ser professor e então entrei pro PIBID, o que me ajudou muito na decisão" (Bolsista licenciando - PIBID/Química, 2013). A escola é reconhecida como o espaço de formação profissional e a reflexão sobre a escolha pela licenciatura envolve a atuação e o desenvolvimento do exercício da profissão. Por esse motivo, a decisão pela docência encontra-se interligada à experiência vivida na sala de aula.

Os professores supervisores, ao avaliar a importância da escrita de histórias de sala de aula no PIBID, dizem que:

As escritas das histórias de sala de aula puderam proporcionar aos bolsistas e ao meu trabalho como supervisora algumas formas de diálogo, ter uma visão dos pensamentos e sentimentos dos outros colegas e com isso rever conceitos e novas formas para o desenvolvimento das atividades realizadas pelo PIBID na escola (Professora supervisora-PIBID/Interdisciplinar-Gestão Escolar, 2013).

A escrita e leitura das histórias de sala de aula nos leva a viver a escola pela perspectiva do outro. Leva-nos a refletir sobre nossas ações e perceber aspectos da escola, dos alunos, dos conceitos desenvolvidos de forma diferente (Professora supervisora - PIBID/Química, 2013)

Como sou constituída e formada nas humanidades, diria que esta é a parte poética do projeto, momento em que desnudamos nossas subjetividades através das histórias que contamos. Acredito que nos construímos na tecitura 
das palavras; penso que as narrativas nos sensibilizam para a docência uma vez que as histórias inventadas ou vividas refletem o universo que envolve as relações professor-aluno, professo-comunidade escolar, professor-pais de alunos, alunos-direções, alunos-pais, alunos-colegas, alunos-funcionários de escola e tantas outras que se constituem na trajetória escolar de cada um de nós (Professora supervisora - PIBID/Francês, 2013)

Os professores supervisores do PIBID/FURG destacam o significado da escrita de histórias de sala de aula como a possibilidade de narrar-se e ter a oportunidade de partilhar suas histórias e aprender com o outro: com os alunos, com os licenciandos e com os outros professores. Por isso, a importância das histórias serem lidas, respondidas, reescritas e conversadas. Contribuindo com essa ideia, Nóvoa (2009, p. 41) aponta que:

Não há respostas feitas para o conjunto de dilemas que os professores são chamados a resolver numa escola marcada pela diferença cultural e pelo conflito de valores. Por isso, é tão importante assumir uma ética profissional que se constrói no diálogo com os outros colegas. É urgente reforçar as comunidades de prática, isto é, um espaço conceptual construído por grupos de educadores comprometidos. Através das comunidades de prática, reforça-se um sentimento de pertença e de identidade profissional que é essencial para que os professores apropriem-se dos processos de mudança e os transformem em práticas concretas de intervenção. É esta reflexão colectiva que dá sentido ao desenvolvimento profissional dos professores.

A carga horária de trabalho do professor no ensino básico não possibilita que a escola proponha comunidades de práticas (NÓVOA, 2009), Rodas de Formação (SOUZA, 2011), momentos de conversas sobre sua prática docente, seus dilemas, dificuldades e questionamentos com que se depara nas diferentes salas de aula onde atua durante sua ação docente. O PIBID proporciona espaços de formação na escola e na universidade, em que participação do professor experiente e atuante na educação básica aliada à formação inicial possibilita aprendizagens e partilha de saberes da docência.

Acredita-se que os espaços de formação são potencializados quando mediados pela escrita, que pode ser narrativa, pois, quando narram sua sala de aula, os professores estão construindo o sentido de pertencer ao espaço escolar, valorizando-se enquanto profissionais da educação. Dessa forma, Suárez (2008, p. 114) sustenta que os professores, 
[...] quando conseguem se posicionar como "antropólogos" de sua própria prática, quando conseguem distanciar-se dela para torná-la objeto de pensamento e podem documentar alguns dos seus aspectos e dimensões "não documentados" percebem o que sabem e o que não conhecem ou não sabem nomear.

A partir das contribuições a respeito do PIBID na visão dos licenciandos e professores supervisores, argumenta-se a importância de continuidade e reconhecimento do PIBID como política de formação docente. Percebe-se, pois, a potência das Rodas de Formação a partir da escrita de histórias de sala de aula, das experiências vividas na escola, da conversa e aprendizagens contribuídas no coletivo. O exercício da escrita narrativa torna-se um trabalho colaborativo e prazeroso, no qual os docentes partilham suas histórias e percebem o que pode ser melhorado e detalhado em cada narrativa.

\section{Conclusão}

Neste texto, defendeu-se a escrita narrativa juntamente a momentos de partilha em Rodas de Formação como fundamentais no processo de formação acadêmico-profissional de licenciandos e professores no PIBID/FURG. A importância da escrita de histórias de sala de aula é destacada pelos participantes como possibilidade de reavaliar ações e de documentar a própria formação. Buscou-se documentar a história de formação de professores no PIBID e, dessa forma, compreender o processo de constituição profissional de professores em Roda, suas aprendizagens construídas no seu processo de formação.

Portanto, acredita-se que as reflexões construídas mostram as contribuições do PIBID como política de formação de professores, que promove uma efetiva parceria entre universidade e escola como lugares de formação docente. O PIBID enriquece esse processo, favorece a compreensão sobre as práticas educativas desenvolvidas na sala de aula, os anseios, dilemas e questionamentos vividos na docência. Como também promove a valorização do exercício do professor, tanto pela sociedade quanto pelos alunos, que buscam a melhoria da educação básica e o reconhecimento profissional. 


\section{Referências}

CLANDININ, Jean; CONNELLY, Michael. Pesquisa Narrativa: experiência e história de pesquisa qualitativa. Tradução: Grupo de Pesquisa Narrativa e Educação de Professores ILEEL/UFU. Uberlândia: EDUFU, 2011.

DINIZ-PEREIRA, Júlio Emílio. A prática como componente curricular na formação de professores. Educação. Santa Maria, v. 36, n. 2, p. 203-218, maio/ago. 2011.

DORNELES, A. A bordadura da sala de aula de Química em Rodas de Formação. Curitiba: Editora Appris, 2013.

DORNELES, A.; GALIAZZI, M.C. Histórias de Sala de Aula de Professoras de Química: Partilha de Saberes e de Experiências nas Rodas de Formação do PIBID/FURG. Química Nova na Escola, vol. 34, n 4, p. 256-265, nov., 2012.

GALIAZZI, Maria do Carmo.; PAULITSCH, Vivian. (orgs). Álbum do PIBID/FURG. Rio Grande: Editora da FURG: 2011.

GALIAZZI, Maria do Carmo.; PAULITSCH, Vivian.; COLARES, Ioni (orgs). Álbum do PIBID/ FURG. Rio Grande: Editora da FURG: 2012.

GALIAZZI, Maria do Carmo.; PAULITSCH, Vivian.; COLARES, Ioni (orgs). Álbum do PIBID/ FURG. Rio Grande: Editora da FURG: 2013.

GALIAZZI, Maria do Carmo.; PAULITSCH, Vivian.; COLARES, Ioni (orgs). Álbum do PIBID/ FURG. Rio Grande: Editora da FURG: 2014.

MORAES, Roque. GALIAZZI, Maria do Carmo. Análise Textual Discursiva. 2. ed. Ijuí: Ed. Unijuí, 2011.

SOUZA, Moacir. Histórias de Professores de Química em Rodas de Formação em Rede: colcha de retalhos tecida em partilhas (d)e narrativas. Ijuí: Editora Unijuí, 2011.

SUAREZ, Daniel. A documentação narrativa de experiências pedagógicas como estratégia de pesquisa-ação-formação de docentes. In: PASSEGI, Maria da Conceição, BARBOSA, Tatyana Mabel Nobre. Narrativas de formação e saberes biográficos. Natal, RN: EDUFRN; São Paulo, SP: Paulus, 2008.

WARSCHAUER, Cecília. Rodas em Rede: oportunidades formativas na escola e fora dela. Rio de Janeiro: Paz e Terra, 2001.

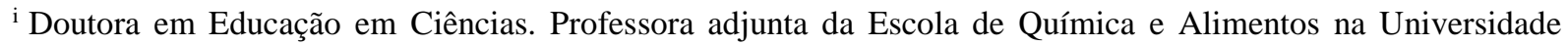
Federal do Rio Grande (FURG). Coordenadora do subprojeto PIBID/Química na FURG.
} 
${ }^{i i}$ Doutora em Educação. Professora Associada da Escola de Química e Alimentos e do Programa de Pós-Graduação em Educação em Ciências na Universidade Federal do Rio Grande (FURG). Coordenadora Institucional do PIBID/FURG.

iii Licenciada em Química pela Universidade Federal do Rio Grande.

${ }^{i v}$ O livro intitulado Narrativas na Docência: a formação acadêmico-profissional em exercício encontra-se no prelo. vAs histórias de sala de aula do PIBID/FURG são narradas, semestralmente, em ambiente virtual de aprendizagem na plataforma Moodle. 